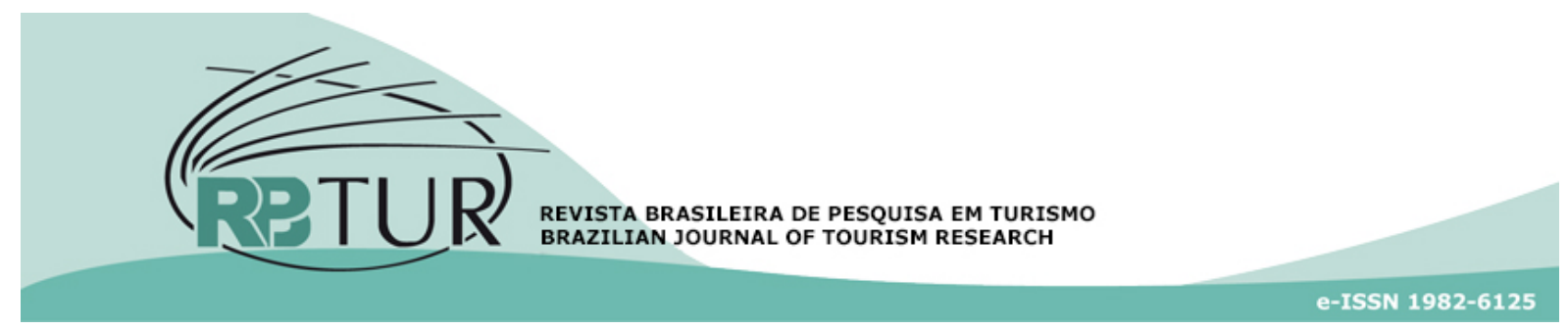

Artigo

DOI: http://dx.doi.org/10.7784/rbtur.v12i2.1403

\title{
Os fãs do Sesc em São Paulo: um estudo sobre hospitalidade e acolhimento
}

Fans of Sesc in São Paulo: a study on hospitality and welcome

Fans del Sesc en São Paulo: un estudio sobre la hospitalidad y la
acogida

Luiz Octávio de Lima Camargo ${ }^{1}$

Airton José Cavenaghi ${ }^{2}$

Danilo Cava Pereira ${ }^{3}$

Elizabeth Kyoko Wada ${ }^{4}$

Resumo: O estudo apresenta os resultados de uma pesquisa empírica na área de hospitalidade e acolhimento que pretendeu traçar um perfil dos participantes de grupos nas redes sociais de fãs do Sesc em São Paulo, centro cultural e de lazer com 41 unidades no estado de São Paulo. A hipótese é a de que este público virtual representa o público prioritário da instituição: o trabalhador do comércio, serviços e turismo, que Prahalad denomina de a base da pirâmide. Para a fundamentação teórica, buscou-se, portanto, em autores de hospitalidade, acolhimento, economia e cultura alguns dos conceitos. Foi elaborado então um questionário com 17 questões - sendo 14 fechadas de múltipla escolha e de mais de uma seleção e 3 abertas -, dividido em três seções: a primeira, que

\footnotetext{
${ }^{1}$ Universidade Anhembi Morumbi (UAM), São Paulo, SP. Professor - colaborador do Programa de Mestrado em Turismo da USP-EACH. São Paulo, SP. Escolha da temática da pesquisa, definição do problema, objetivo e procedimentos metodológicos da pesquisa, redação do texto, análise e interpretação dos dados.

${ }^{2}$ Universidade Anhembi Morumbi (UAM), São Paulo, SP. Auxilio na conceituação de hospitalidade e acolhimento e na definição das implicações desses conceitos para uma instituição como o Sesc.

${ }^{3}$ Universidade Anhembi Morumbi (UAM), São Paulo, SP. Concepção do problema e objetivos da pesquisa, aplicação da mesma, análise dos resultados e redação do artigo.

4 Universidade Anhembi Morumbi (UAM), São Paulo, SP. Pesquisadora do Instituto de Pesquisa e Desenvolvimento Social e Tecnológico (ISAM). Embasamento teórico para os conceitos de hospitalidade no contexto comercial, serviços, gêneros e base da pirâmide, cujas discussões se desenvolveram no grupo de pesquisa Hospitalidade na Competitividade em Serviços e em sala de aula na disciplina Gestão e Planejamento Estratégico da Hospitalidade, durante a qual se desenvolveram o seminário, a pesquisa e o artigo com a temática e o objeto propostos.
}

Artigo recebido em: 09/01/2018. Artigo aceito em: 22/02/2018.

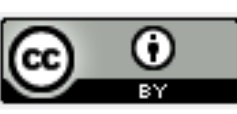


limava quem não participava de nenhum dos grupos do Facebook selecionados; a segunda, para traçar um breve perfil socioeconômico; e a terceira, que procurou entender melhor a assiduidade e participação na programação das unidades do Sesc no estado de São Paulo. A pesquisa ficou disponível de 26 de novembro a 4 de dezembro de 2017, totalizando 224 respostas válidas. De caráter estatístico e exploratório para posterior análise descritiva, o questionário foi aplicado em três grupos de fãs selecionados por número de participantes. Ao final das análises, pôde-se apresentar um breve panorama do perfil do aficionado pelo Sesc, participante de grupos do Facebook, e que percebem as relações de hospitalidade e acolhimento dos funcionários da instituição.

Palavras-chave: Hospitalidade. Acolhimento. Centro Cultural. Fã. Base da pirâmide

Abstract: The study presents the results of an empirical research in the area of hospitality and reception that intended to outline a profile of the participants of social networks' groups of fans of Sesc in São Paulo, cultural and leisure center with 41 units in the state of São Paulo. The hypothesis is that this virtual group represents the institution's priority public: the trade, service and tourism worker, whom Prahalad calls the the pyramid bottom. For the theoretical basis, some of the concepts were sought in authors of hospitality, economics and culture. A questionnaire was then prepared with 17 questions - 14 of which were multiple-choice and with more than one selection and 3 were open - divided into three sections: the first one, that selected those who participated in any of the selected Facebook groups; the second, to outline a brief socioeconomic profile; and the third, which sought to better understand attendance and participation in the activities of the Sesc in the state of São Paulo. The research was available from November 26 to December 4, 2017, with 224 valid answers. From a statistical and exploratory character for subsequent descriptive analysis, the questionnaire was applied in three groups of fans selected by number of participants. At the end of the analysis, it was possible to present a brief overview of the profile of the fan of Sesc, participant of groups of Facebook, and that perceive the relations of hospitality with the employees of the institution.

Keywords: Hospitality. Reception. Cultural Center. Fan. Pyramid bottom.

Resumen: El estudio presenta los resultados de una investigación empírica en el área de hospitalidad y acogida que pretendió trazar un perfil de los participantes de grupos en las redes sociales de fans del Sesc en São Paulo, centro cultural y de ocio con 41 unidades en el estado de São Paulo. La hipótesis es que este público virtual representa al público prioritario de la institución: el trabajador del comercio, servicios y turismo, que Prahalad denomina la base de la pirámide. Para la fundamentación teórica, se buscó, por lo tanto, en autores de hospitalidad, acogida, economía y cultura algunos de los conceptos. Se elaboró entonces un cuestionario con 17 preguntas - siendo 14 cerradas de múltiple elección y de más de una selección y 3 abiertas -, dividido en tres secciones: la primera, que limaba quien no participaba de ninguno de los grupos de Facebook seleccionados; la segunda, para trazar un breve perfil socioeconómico; y la tercera, que intentó comprender mejor la asiduidad y participación en la programación de las unidades del Sesc en el estado de São Paulo. La encuesta estuvo disponible desde el 26 de noviembre al 4 de diciembre de 2017, con 224 respuestas válidas. De carácter estadístico y exploratorio para posterior análisis descriptivo, el cuestionario fue aplicado en tres grupos de fans seleccionados por número de participantes. Al final de los análisis, se pudo presentar un breve panorama del perfil del aficionado por el Sesc, participante de grupos de Facebook, y que perciben las relaciones de hospitalidad y acogida de los funcionarios de la institución.

Palabras-clave: Hospitalidad. Acogida. Centro Cultural. Fan. Base de la pirámide.

\section{INTRODUÇÃO}

O presente estudo apresenta os resultados de uma pesquisa empírica na área de hospitalidade que pretendeu, de forma exploratória, medir a satisfação dos autoproclamados fãs do Sesc em São Paulo, centro cultural e de lazer com 41 unidades no estado de São Paulo (Sesc São Paulo, 2017). Como fundamentação teórica, buscou-se 
conceitos sobre hospitalidade e acolhimento, a base da pirâmide (Prahalad, 2017) e centros culturais.

O objetivo, então, é apresentar um panorama do perfil do aficionado pelo Sesc, presente em grupos da rede social Facebook, frequentadores da instituição que percebem as relações de hospitalidade e acolhimento dos funcionários, aqui representando o anfitrião.

Este relacionamento positivo é importante para qualquer estabelecimento comercial ao criar vínculos com o cliente, possibilitando assim um relacionamento mais genuíno de troca, mesmo que financeira (BinetMontandon, 2011; Gotman, 2009; Telfer, 2004). Por esse motivo, justifica-se a pesquisa sobre os impactos da hospitalidade na experiência e na vivência de consumo de cultura e entretenimento desse frequentador de centros culturais.

O questionário aplicado tinha o objetivo de conhecer melhor o perfil socioeconômico e a vivência dos frequentadores nas unidades do Sesc que participam dos grupos "Aficionados pelo SESC-SP", "SESC" e " SESC Troca de ingressos".

Considerando, então, esse fã participante de grupos nas redes sociais, a hipótese a ser testada é a de que esse universo online representa o universo físico do público frequentador prioritário da instituição Sesc em São Paulo: o trabalhador do comércio, serviços e turismo, em sua maioria de baixa e média renda, representado aqui pela base da pirâmide de $\mathrm{C}$. K. Prahalad.
Nas próximas páginas, a fundamentação teórica em hospitalidade, acolhimento, centro cultural, fãs e a base da pirâmide ajudam a embasar a pesquisa e analisar os resultados para testar a hipótese. Ao final, pretende-se voltar ao objetivo para avaliar se ele foi alcançado e se há alguma consideração para futuras pesquisas, principalmente porque o presente artigo apresenta um estudo exploratório e descritivo de uma análise estatística.

\section{HOSPITALIDADE E ACOLHIMENTO EM CENTROS CULTURAIS}

Para este estudo, os conceitos são trabalhados em um cenário que, a partir de agora, será chamado de cena da hospitalidade (Camargo, 2004; Montandon, 2011). Neste contexto, o encontro será estudado em quatro fases (chegada, recepção, presente e despedida), escolhidas dentre as observadas por Montandon por serem coerentes com a realidade do objeto (Sesc em São Paulo). Tudo isso considerando ainda os tempos, também trazidos nos escritos de Montandon (2011), de acolher, ficar e partir. Como atores deste encontro, os papéis de anfitrião e hóspede são representados aqui por, respectivamente, o funcionário do Sesc e o frequentador-visitante da unidade. A figura 1 representa, graficamente, este esquema. 
Figura 1 - A cena da hospitalidade no Sesc em São Paulo

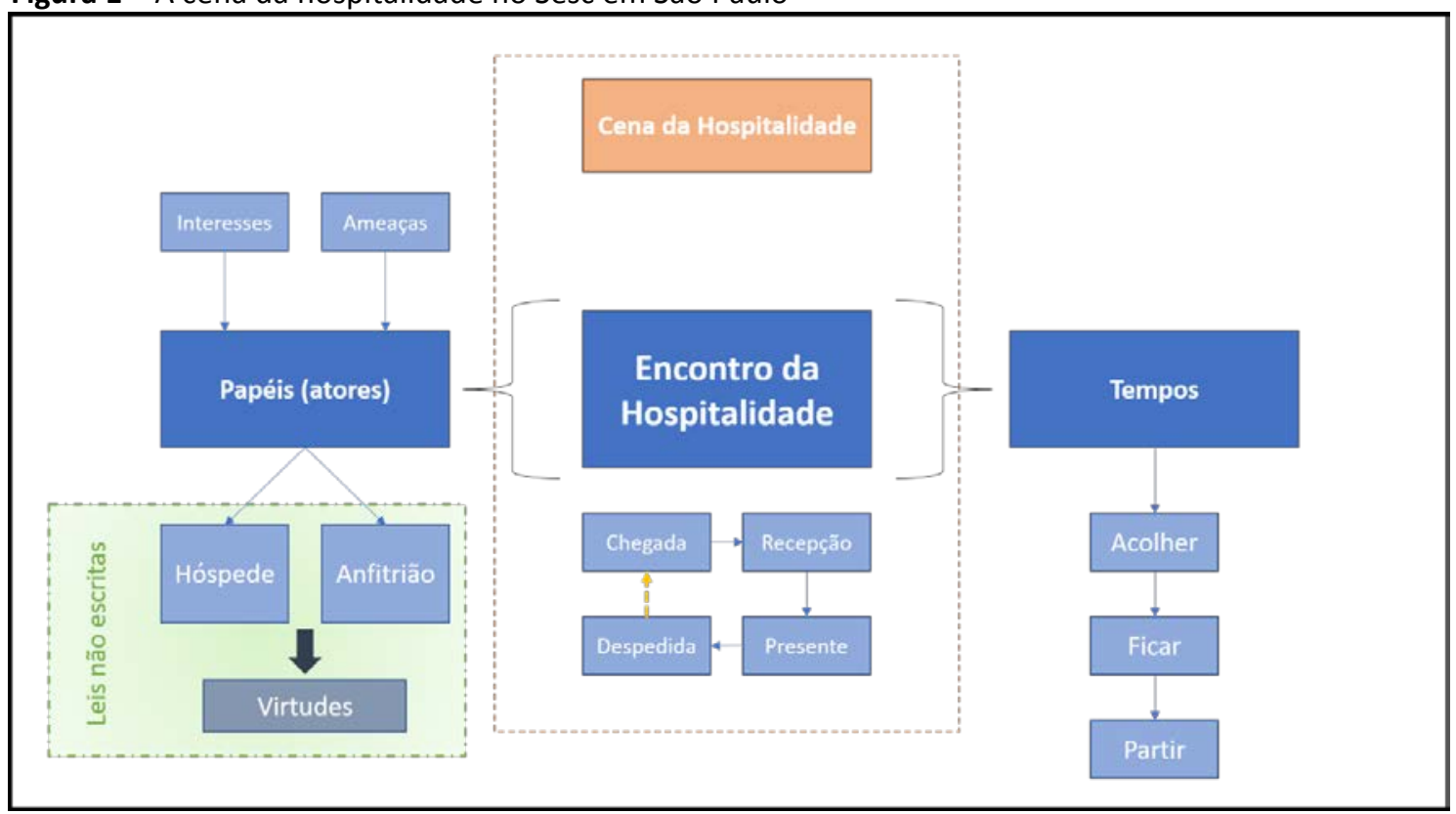

Fonte: Elaborado pelos autores

Por se tratar de um estudo da hospitalidade em um ambiente comercial, permeando ainda ambos os domínios comercial e social, definidos por Lashley (2004) e Camargo (2004), já que encontra-se um espaço de convivência nestes centros culturais, a opção para conceituar hospitalidade neste contexto se vale de autores que pensam tanto o ambiente onde a troca pressupõe um retorno financeiro, como os ingleses e os americanos, quanto os que preferem estudar a sociedade, suas culturas e costumes, como os franceses. Portanto, os principais autores escolhidos foram Pitt-Rivers (2012), que trata das leis da hospitalidade, Boudou (2012), ao falar de ritos e tipos de hóspede e anfitrião e Telfer (2004) para falar das características de ser hospitaleiro (hospitabilidade).

Para trabalhar os conceitos de acolhimento, pensando ainda no cenário de uma instituição privada e cultural-social, os autores estudados para a fundamentação teórica são: Binet-Montandon (2011), que se preo- cupa com o vínculo social através da acolhida e Grassi (2011), que apresenta a passagem do exterior para o interior e o ritual do acoIhimento, assim como Boudou (2012) aborda os ritos da hospitalidade.

"A Hospitalidade é uma maneira de viver em conjunto, regida por regras, ritos e leis" (Montandon, 2011, p.31). Dentre a extensa etimologia da palavra hospitalidade, Benveniste (1995) encontra um elo com os estudos de Mauss em seu Ensaio sobre a dádiva, em que estuda os laços que se criam entre povos diferentes, com pessoas por vezes desconhecidas, em um encontro acontecendo no espaço físico-geográfico de um ou de outro. Tanto Mauss (2003) quanto Benveniste citam o ritual do potlach - o ato de dar o que se tem aos outros da comunidade como forma de retribuição por ter ganhado tudo aquilo em primeiro lugar. Então, estudando palavras de diversas línguas e etnias, palavras como hóspede, hospedeiro, possuir, estrangeiro hostil e inimigo, aparecem para significar esse encontro entre desconheci- 
dos, ou não.

Montandon (2011) lembra a observação de Homero, em Odisseia, sobre o comportamento do visitante e de quem recebe neste ritual, a cena da hospitalidade. Dentre as microcenas que seguem fórmulas e regras, desdobra-se aqui quatro delas: a chegada, a recepção, a entrega dos presentes e as despedidas; já que as outras fases se atêm mais a uma hospitalidade em domínio doméstico ou ainda quando se há hospedagem.

A primeira fase desse encontro, em um ambiente comercial e social como um centro cultural, pode ser a chegada: "tudo começa naquela soleira, naquela porta à qual se bate e que vai se abrir para um rosto desconhecido, estranho" (Montandon, 2011, p. 32). Esta fase também conversa com a de Boudou (2017), a separação, dando a oportunidade de aproximação. Ao chegar, o hóspede está a meio caminho de um estranho hostil e o de um membro da comunidade (Binet-Montandon, 2011).

A recepção oferece o atendimento, o acolhimento depois da passagem, que Boudou também denomina de "a margem", mais bem expressa pelo tempo, de espera, do que pelo espaço. No caso do estabelecimento comercial, a recepção é quando o visitante se sente acolhido e bem-vindo àquele espaço.

Assim que a hospitalidade toma forma, o presente pode se dar em um gesto, algo que difere o acolhimento de outro qualquer. É neste momento que a dádiva se manifesta: o anfitrião presenteia o hóspede, que ao receber o presente se sente na obrigação de contribuir, seja também com um gesto ou ainda com outra manifestação. Porém, para que essa reciprocidade é preciso lembrar que a dádiva e a contradádiva estão espaçados no tempo, pois a hospitalidade "supõe uma relação unidirecional do anfitrião ao convidado" (Boudou, 2017, p. 113).

Já é hora da despedida. Montandon lembra da regra dos três dias que muitas culturas tomam como provérbio, já que esse tempo define "o quadro e os limites: um tempo para acolher, um tempo para ficar, um tempo para partir" (2011, p.34). Ainda segundo o autor, a hospitalidade não objetiva a integração, fica entre os limites da rejeição e da absorção. Nesta lógica, o estrangeiro vai, pouco a pouco se tornando um membro da comunidade; mas ao mesmo tempo, se se estabelece um espaço simbólico na comunicação, o hóspede sempre vai ser estrangeiro no grupo (Binet-Montandon, 2011). Boudou reforça essa ideia de que a hospitalidade cessa quando o hóspede se integra quando diz que ela ajuda a resolver:

o dilema de um encontro que não pode levar a integração (seria necessário um casamento, por exemplo), outorgando ao estrangeiro um estatuto demasiado importante para ser temporário. [...] a comunidade hierarquiza esta relação e a torna legítima pela hospitalidade. (Boudou, 2017, p. 111)

É claro que em um estabelecimento comercial que não oferece hospedagem o tempo de partir é outro, mas a ideia de que após a pessoa ser recebida e ter ficado para aproveitar o serviço ou produto é hora de partir.

E como em toda cena, tem-se os atores. Neste caso, os papéis são de anfitrião e hóspede, que se valem de ritos, através de costumes e tradições, para regrar o relacionamento de forma positiva (hospitalidade) ou negativa (hostilidade). 


\subsection{Os papéis na cena da hospitalidade}

No encontro, como explicado anteriormente, os atores aqui estudados serão o funcionário do Sesc, representando o anfitrião, que recebe seu hóspede/convidado, o frequentador. Mesmo os papéis podendo se inverter em situações diversas, ou ainda termos o anfitrião recebendo outro hóspede (um colega novo, um fornecedor, um artista, etc), a opção deste autor neste contexto é entender o segundo como o visitante; cliente do ponto de vista comercial, frequentador aos olhos da instituição.

Ambos os participantes desta cena possuem seus interesses nessa relação, sejam eles pertinentes ou não pertinentes à hospitalidade (Lashley, 2004; Telfer, 2004), tendo em vista que há obrigações mútuas e se espera uma reciprocidade em leis não escritas (Pitt-Rivers, 2012; Lashley, 2004), mas que são seguidas pela tradição cunhada pela cultura de cada povo ou região, como a circulação da dádiva de Mauss (2003): um dá e o outro recebe. Esses motivos, como elucida Telfer (2004), devem ser generosos para haver ali uma verdadeira intenção de receber bem, o que demonstra as características de ser hospitaleiro no anfitrião, conjunto esse denominado por ela de hospitabilidade. Já no caso do visitante, por não se tratar de um espaço de hospedagem, mas que mesmo assim acolhe, a classificação dos tipos de estrangeiro de Boudou (2017) aponta melhor este ator na cena, segundo suas intenções. Como essas intenções podem ser diversas optou-se por escolher as formas mais adequadas de chegada deste estranho a um estabelecimento comercial: recém-chegado (a iniciar), perigo (a eliminar), convidado (a acolher), diferença (a compreender) e finalmente o próprio estranho (a familiarizar-se). Ao mesmo tempo, anfitrião e hóspede, pelo desconhecimento, são uma ameaça um para o outro. Boudou (2017) também explica que o estrangeiro, o estranho, pode se apresentar como um risco para a sociedade em que chega, já que à primeira vista não se sabe suas intenções. Do outro lado, o anfitrião também é uma incógnita, pois ele pode ser tanto hospitaleiro quanto hostil.

Neste sentido, os motivos ou interesses de cada um dos atores contribuem para uma relação de hospitalidade ou hostilidade, e cabe, então, à empresa anfitriã cuidar para que a hospitalidade seja presente em seus funcionários. Dessa forma a hospitalidade poderá ser mais recorrente nas relações de troca com este visitante desconhecido que chega.

Há, ainda, casos em que o frequentador deste estabelecimento cria um laço com o espaço, a empresa e seus funcionários, ou seja, com o anfitrião, que passa de estranho a amigo. Telfer (2003, p. 65), fala do acolhimento como forma de ser amigável (pensando na relação do anfitrião com seus hóspedes), oferecendo uma certa intimidade, "uma quota da vida doméstica do hospedeiro". Essa sensação de sentir-se em casa e de fazer o outro se sentir em casa pode transformar o hóspede em um anfitrião, quando este está tão à vontade que convida outros conhecidos para visitar o espaço, tornandose assim um anfitrião também, mesmo que temporariamente. Para esta relação, Lugosi (2008) deu o nome de metahospitalidade, quando estudou o comportamento de fre- 
quentadores de estabelecimentos comerciais de alimentação que trocavam de papeis por alguns momentos quando se sentiam bem acolhidos naquele espaço.

Ainda falando dessa relação do anfitrião com seus convidados, tanto Boudou (2017) quanto Pitt-Rivers (2012) falam de leis e ritos que a permeiam. A tradição e a cultura de cada povo trazem leis que, apesar de não terem sido transcritas, são inatas naquela comunidade e regulamentam um código moral e ético de acolhida. Boudou acrescenta que "a hospitalidade ritual procede de uma hierarquia invertida que labora pela dupla tarefa de tornar possível a sociabilidade intergrupal preservando a integridade intragrupo" (2017, p. 104). Ou seja, a hospitalidade funciona como um ritual de elementos contraditórios - a certeza do encontro e a incerteza das intenções -, que é identificável, é passível de repetição, e tem seus atores dentro de um espaço e durante um período de tempo. A hospitalidade, então, age como uma proteção para ambos os atores neste encontro, "é gesto de compensação, de igualização, de proteção" (Grassi, 2011, p. 45), já que o desconhecido se torna conhecido e as relações podem se dar normalmente (e de forma mais positiva, como esperado) depois desses ritos de passagem: da rua à soleira e da soleira ao interior, "a soleira marca uma fronteira, uma passagem, e sua transposição implica tacitamente, para o convidado, a aceitação das regras do outro" (Montandon, 2011, p. 32).

\section{A BASE DA PIRÂMIDE E OS FÃS DO SESC}

Este convidado, neste contexto, é o fã do Sesc. Apesar de conhecer bem o anfitrião (a instituição) ele ainda é desconhecido pela empresa. Entre eles, porém, há uma interação mediada pelas redes sociais e uma relação positiva entre pertencimento a essa comunidade e bem-estar (Chadborn, Edwards, \& Reysen, 2017; Reysen, Plante, \& Chadborn, 2017). Esse público que se relaciona em suas comunidades de fãs tem um interesse em comum (Chadborn et al., 2017) e, no caso, temse a programação de um centro cultural e desportivo. E quem seria esse fanático que usufrui de atividades gratuitas de lazer?

"Mais de 4 bilhões de pessoas vivem na BP [base da pirâmide], com menos de US\$2 por dia" (Prahalad, 2017, p. 48). A premissa é que o público prioritário do Sesc - trabalhadores do comércio, serviços e turismo se encaixaria nesse conceito. Prahalad estuda a pirâmide econômica que ilustra a capacidade de geração de renda no mundo e aponta para essa massa como uma oportunidade de mercado que representava cinco triIhões de dólares de poder de compra, em 2005.

Conhecer esse cliente, então, através de parcerias entre pequenas e grandes empresas dos setores privado e do terceiro setor, é imprescindível e, ao fazer isso, tornamse relevantes para a comunidade local, já que conseguem produzir e vender com qualidade. Dessa forma, Prahalad entende que é possível ter lucro e erradicar a pobreza no mundo, mas, por exemplo, no caso do Brasil, como cita Karnani (2016), essa linha de pobreza não significaria o mesmo para nós, pois seríamos pobres com renda anual menor que 3.927 dólares. Isso incluiria as classes C, D e E e faria com que a base da pirâmide fosse superestimada.

Mesmo assim, para esse grupo a au- 
tonomia afeta positivamente a satisfação com a vida (Martin \& Paul Hill, 2012), por isso a consonância com a política da instituição de promover a autonomia pessoal e a interação, valorizando as pessoas (Sesc São Paulo, 2017).

\section{CENTROS CULTURAIS - O SESC EM SÃO PAULO}

Os centros culturais são espaços para fazer a cultura viva (Coelho, 1986, apud Silva, 2013). Uma construção coletiva de interações humanas e, portanto, dinâmica. Neste contexto, insere-se o Sesc no estado de São Paulo.

Desde 1946, ano de criação do Serviço Social do Comércio - Sesc pelo empresariado do comércio e serviços (Sesc São Paulo, 2017), a instituição introduziu modelos inovadores de cultura e educação não formal. Da cultura erudita à cultura popular, do turismo social à educação ambiental, dos programas de saúde aos programas voltados a diferentes faixas etárias e do esporte ao lazer, a programação de atividades e serviços oferecidas visa atender todos os públicos, contribuindo para criar experiências duradouras e significativas. Com 41 centros culturais e desportivos (até dezembro 2017 e ainda em expansão) no estado de São Paulo, desenvolve ações de educação informal e permanente "com intuito de valorizar as pessoas ao estimular a autonomia pessoal, a interação e o contato com expressões e modos diversos de pensar, agir e sentir" (Sesc São Paulo, 2017), a instituição também conta com programas pioneiros, como o Mesa Brasil, que recolhe doações de alimentos de empresas e as leva a entidades assistenciais de- vidamente assessoradas pela equipe nutricional do Sesc. As atividades são complementadas com ações online do Portal SescSP, programação do SescTV, produtos das Edições Sesc e do Selo Sesc, além da revista E e dos periódicos Mais 60 e Cadernos de Cidadania, que divulgam e registram a ação do Sesc ultrapassando as instalações físicas das unidades.

No início de suas atividades, a instituição atendia somente os funcionários do comércio e serviços, entretanto, com o passar do tempo, o atendimento se estendeu a toda a comunidade, sem deixar de lado seu público prioritário, agora também os trabalhadores do setor de turismo. Em 2013, a instituição volta sua atenção aos então chamados de comerciários, ou seja, os trabalhadores do comércio de bens, serviços e turismo, limitando o acesso em certos espaços e atividades aos demais clientes, a fim de garantir o atendimento ao seu público principal.

\section{PROCEDIMENTOS METODOLÓGICOS}

Em novembro de 2017, a pesquisa quantitativa de caráter exploratório foi realizada em três grupos no Facebook, selecionados por número de participantes e, principalmente, pelo mote: fãs do Sesc. Um questionário com 17 questões abertas e fechadas, montado no Google Formulário, foi aplicado na rede social de $26 / 11$ a $04 / 12$. O objetivo foi conhecer melhor o perfil socioeconômico e a vivência dos frequentadores nas unidades do Sesc que participam dos grupos na rede social.

A pesquisa estatístico-descritiva continha 17 perguntas, sendo 14 fechadas de múltipla escolha e de mais de uma seleção e 
3 abertas, sendo a primeira pergunta (Você participa de qual grupo relacionado ao Sesc?) eliminatória, visto que a ideia era conversar com o público daqueles grupos apenas em um primeiro momento. Dessa forma, dentre as formações de fãs do Sesc que se apresentam no Facebook com maior número de participantes foram pré-selecionadas quatro:

1) Aficionados pelo SESC-SP - 3.947 membros (em 16/11/2017)

Administradores (não funcionários):

Valdeci e Márcio

2) SESC - Troca de Ingressos - 2.037 membros (em 16/11/2017)

Administradores (não funcionários): Tadeu, Taciana e Rodrigo

3) SESC - 1.061 membros (em 16/11/2017)

Administrador (ex-funcionário): Vanderlei

4) "Das Antigas" Sesc - 505 membros (16/11/2017)

Administradores (funcionários): Umberto, Maria e Vanessa

E então, para obter um resultado mais justo, foi descartado o grupo "Das Antigas" Sesc por ter funcionários ativos como administradores e que, portanto, poderiam influenciar as postagens e moderação das mesmas. Também era o grupo com menos membros, o que facilitou a exclusão na pesquisa.
Os três grupos selecionados para a pesquisa foram: Aficionados pelo SESC-SP, SESC - Troca de Ingressos e SESC. Todos têm postagens divulgando programações, além de outras mais específicas, como oferta de ingressos para compra e venda (Tricolor, Ferreira, \& Oliba, [s.d.]).

O questionário foi dividido em três seções: a primeira, que limava quem não participava de nenhum dos grupos selecionados; a segunda, de perfil socioeconômico; e a terceira, que procurou entender melhor a assiduidade e participação na programação das unidades do Sesc no estado de São Paulo; mesmo os grupos podendo conter membros de outros estados (Gomes, [s.d.]).

A publicação do link nos grupos aconteceu no dia 26 de novembro de 2017 e o retorno foi imediato, totalizando, no período total, 243 respostas. Destas, 224 foram validadas, ou seja, participações de quem realmente era membro do grupo.

Os resultados demonstram uma amostra desse universo dos grupos de fãs do Sesc em São Paulo, conforme análise que se segue.

\section{ANÁLISE DOS RESULTADOS}

A primeira pergunta balizava a pesquisa a fim de analisar as respostas somente daqueles membros dos grupos selecionados. 


\section{Você participa de qual grupo relacionado ao Sesc?}

243 respostas

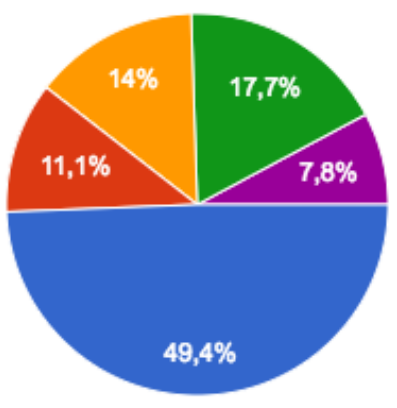

Aficcionados pelo SESC-SP

SESC - Troca de Ingresso

SESC

Participo de mais de um dos grupos citados

Năo participo de nenhum dos grupos citados

Fonte: Dados da pesquisa

Dos respondentes válidos (224 de $243)$, a maioria $(49,4 \%)$ era do grupo de maior número, o que justificaria essa maior participação. Afinal, o administrador Márcio Nunes Ribeiro deixa claro o objetivo do grupo, o de propiciar conhecimento, encontro, amizade, partilha, e generosidade entre os Aficionados pelo Sesc-SP (Ribeiro \& Silva, [s.d.]). Nota-se, inclusive, que é o grupo mais participativo e organizado, compartilhando informações relevantes para todos.

Dezenove pessoas responderam à pesquisa sem participar de nenhum grupo, muito provavelmente por terem sido marcadas nos comentários por membros do grupo, já que as postagens não ficam fechadas para o público externo.

A segunda fase compreendia as perguntas que analisam o perfil socioeconômico dos respondentes em oito perguntas, sendo uma delas exclusiva para quem tem a credencial plena (a matrícula do Sesc), para descobrir se era titular ou dependente da matrícula.

Gráfico 2 - Pergunta 2 - Credencial plena

\section{Você tem a credencial plena (é comerciário matriculado no Sesc)?}

\section{4 respostas}

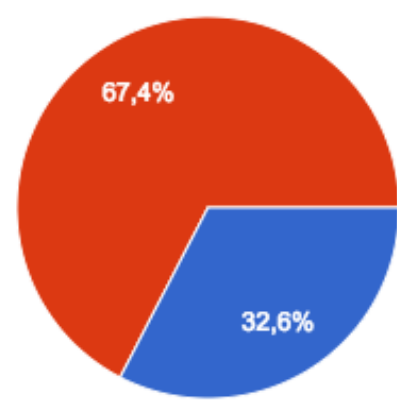

Não

Sim

Fonte: Dados da pesquisa 
A maioria, 151 pessoas, respondeu positivamente, mostrando que os grupos formados são basicamente de pessoas trabalhadoras do comércio, serviços e turismo, matriculados no Sesc. Desse número, 122 pessoas eram titulares.
O próximo questionamento foi sobre a idade, com opções que mostrassem o adolescente (menos de 18 anos); o jovem adulto (de 18 a 29 anos); o adulto de 30 a 59 anos dividido em duas partes; e o idoso, com mais de 60 anos.

Gráfico 3 - Pergunta 3 - Idade

\section{Qual é a sua idade?}

\section{4 respostas}

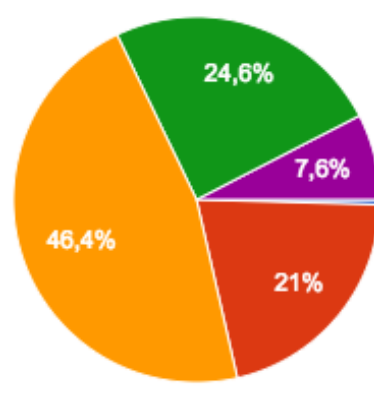

Menos de 18 anos

De 18 a 29 anos

De 30 a 45 anos

De 45 a 59 anos

Mais de 60 anos

Fonte: Dados da pesquisa

O resultado demonstra que quase não há adolescentes no grupo (apenas 1), já que em teoria a entrada na rede social aqui estudada deveria ser apenas de pessoas adultas, com mais de 18 anos. Outro resultado baixo foi o de idosos, que apenas 17 responderam o questionário. O perfil, então, é de pessoas adultas, em sua maioria entre 30 e 45 anos.

Para a próxima pergunta, qual o gênero, optou-se por oferecer uma variedade maior do que a usual na pesquisa, a fim de conhecer o real perfil dos fãs e considerando que o público do Sesc é bem diversificado (como já demonstrado pelo gráfico 3, sobre a idade).

Gráfico 4-Pergunta 4 - Gênero

4. Com qual gênero você se identifica?

224 respostas

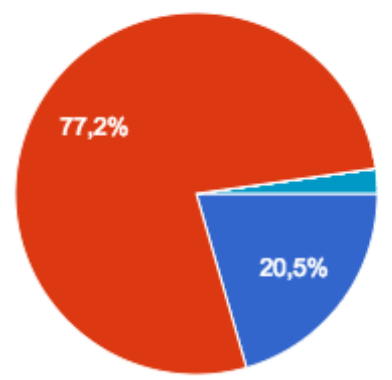

Masculino Cisgênero (homem que se identifica com o gênero que lhe foi....

- Feminino Cisgênero (mulher que se identifica com o gênero que lhe foi...

- Masculino Transge̊nero (homem que năo se identifica com o gênero que...

- Feminino Transgênero (mulher que năo se identifica com o gênero que..

Não Binário (pessoa que não se ide..

Outro não relacionado acima

Fonte: Dados da pesquisa 
Foram oferecidas seis opções, que contemplavam os gêneros masculino cis e transgênero, feminino cis e transgênero, o não binário e outro não relacionado. O perfil, então, foi de mulheres cisgênero (dois terços), e apenas cinco pessoas responderam que não se identificavam com nenhum dos gêneros apresentados (2,2\%).

A escolaridade foi a próxima questão, demonstrando um bom reflexo da educação nessa comunidade estudada.

Gráfico 5 - Pergunta 5 - Escolaridade

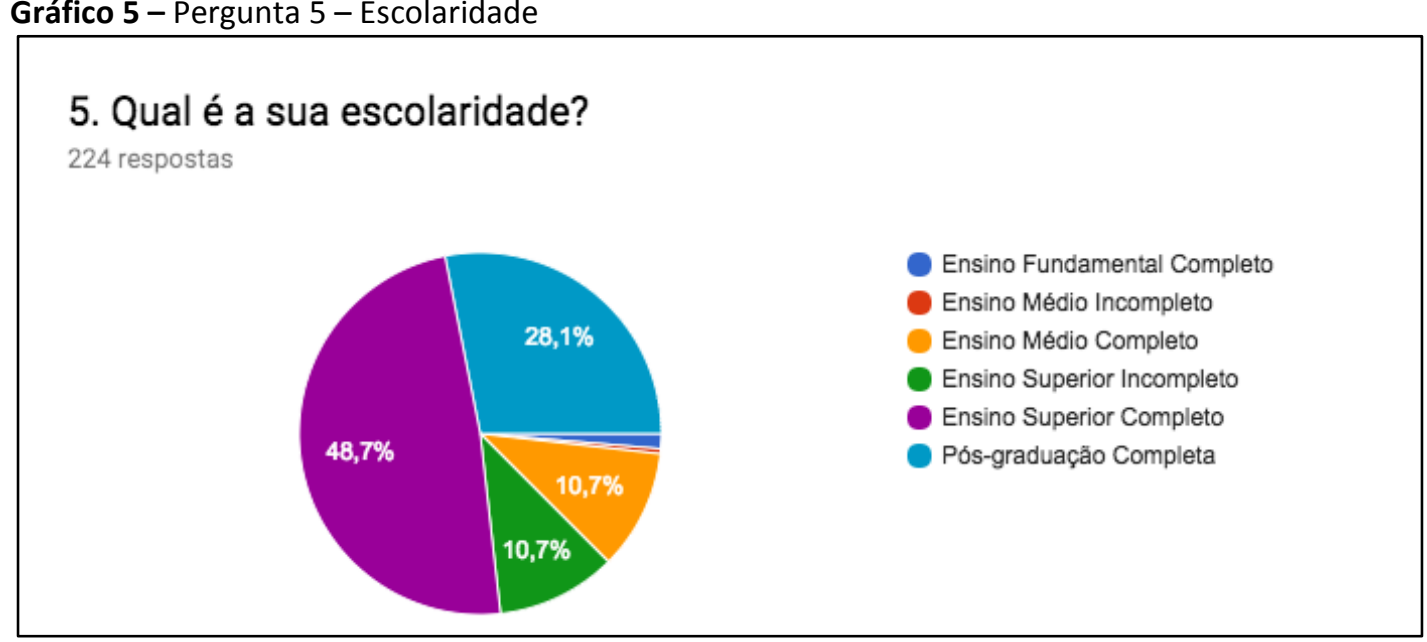

Fonte: Dados da pesquisa

Dentre os respondentes apenas 4 não tinham completado ou o ensino fundamental ou o médio, e 109 tinham uma graduação, representando quase metade da amostra. Esse universo pode não ser o mesmo de credenciados e visitantes das unidades desse centro cultural, porém, como os grupos comparti-
Iham muita divulgação de espetáculos e outros eventos culturais, percebe-se que a escolaridade é um fator de repertório para os interessados na programação do Sesc.

Outra questão que reflete um público diferenciado neste recorte é a sexta, sobre se o respondente é o mantenedor da família.

Gráfico 6 - Pergunta 6 - Mantenedor da família

6. Você é o principal mantenedor da família?

\section{4 respostas}

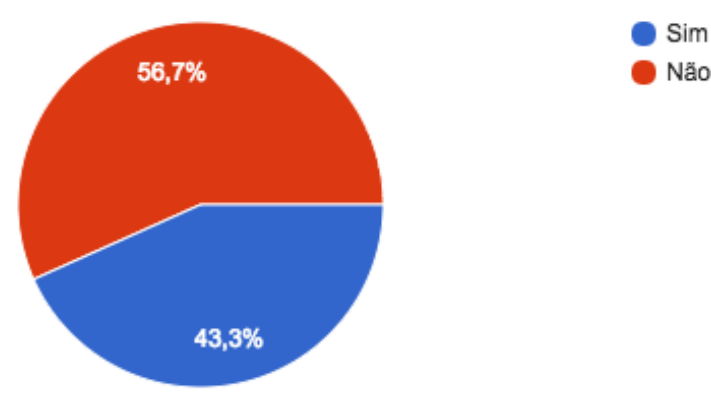

Fonte: Dados da pesquisa 
A resposta de 97 , contra 127 , de não responsáveis principais pela família pode mostrar respondentes ainda dependentes da família, já que são em sua maioria jovens (até 45 anos são 152 dentre 224).
A renda familiar é a questão que mais representaria aqui o público principal do Sesc, o correspondente à base da pirâmide de Prahalad. A pergunta sete mediu a renda da amostra.

Gráfico 7 - Pergunta 7 - Renda familiar

\section{Qual é a sua renda familiar?}

\section{4 respostas}

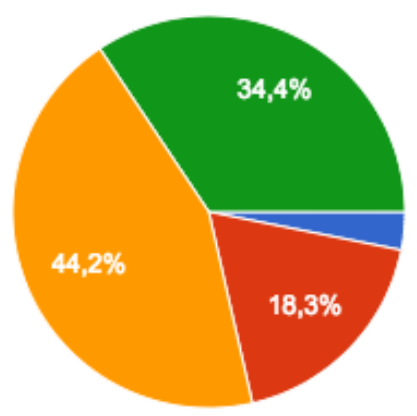

Menos de um salário mínimo (até R\$ 937,00 )

De um a dois salários mínimos (de R\$ 937,00 a R\$ 1874,00 )

De 2 a 5 salários mínimos (de RS 1874,00 a R $\$ 4.685,00$ )

Mais de 5 salários mínimos (mais de $\mathrm{R} \$ 4.685,00$ )

Fonte: Dados da pesquisa

Quase $80 \%$ dos respondentes ganham entre 1.874 e 4.685 ou mais, somando a renda de toda a família. No Brasil, considerando o Critério Brasil (Associação Brasileira de Empresas de Pesquisa, 2016), a amostra estaria dominantemente nas classes socioe- conômicas C e B, ou seja, um alto poder aquisitivo.

O último gráfico apresenta a pergunta sobre quantas pessoas existem no grupo familiar.

Gráfico 8-Pergunta 8-Pessoas na família

8. Quantas pessoas há na sua família?

224 respostas

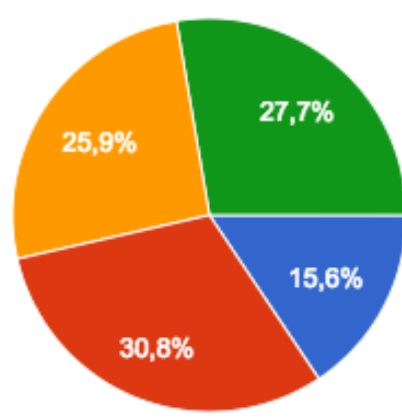

Fonte: Dados da pesquisa 
Quase metade da amostra tem até duas pessoas, um reflexo de pequenas famílias hoje no Brasil, só de casais e com poucos filhos (a resposta com mais pessoas na família, 4 ou mais, teve 62 respondentes).

Este resultado socioeconômico apresenta um público de classe social alta, dependente da família e jovem adulto. Como a família tem poucos membros e há uma alta escolaridade nos resultados, talvez a maioria dos respondentes possam ser de estudantes que moram sozinhos e são sustentados pela família, que mora em outra cidade. Então, se- gundo a hipótese levantada no início da pesquisa, a de que esse universo online representa o universo físico do público frequentador prioritário da instituição Sesc em São Paulo, o pobre e trabalhador de baixa e média renda da base da pirâmide de Prahalad, pode-se afirmar que ela não se sustenta e, portanto, pode ser refutada.

A terceira e última sessão, sobre a vivência do frequentador do Sesc nas unidades, começa com a pergunta sobre a frequência.

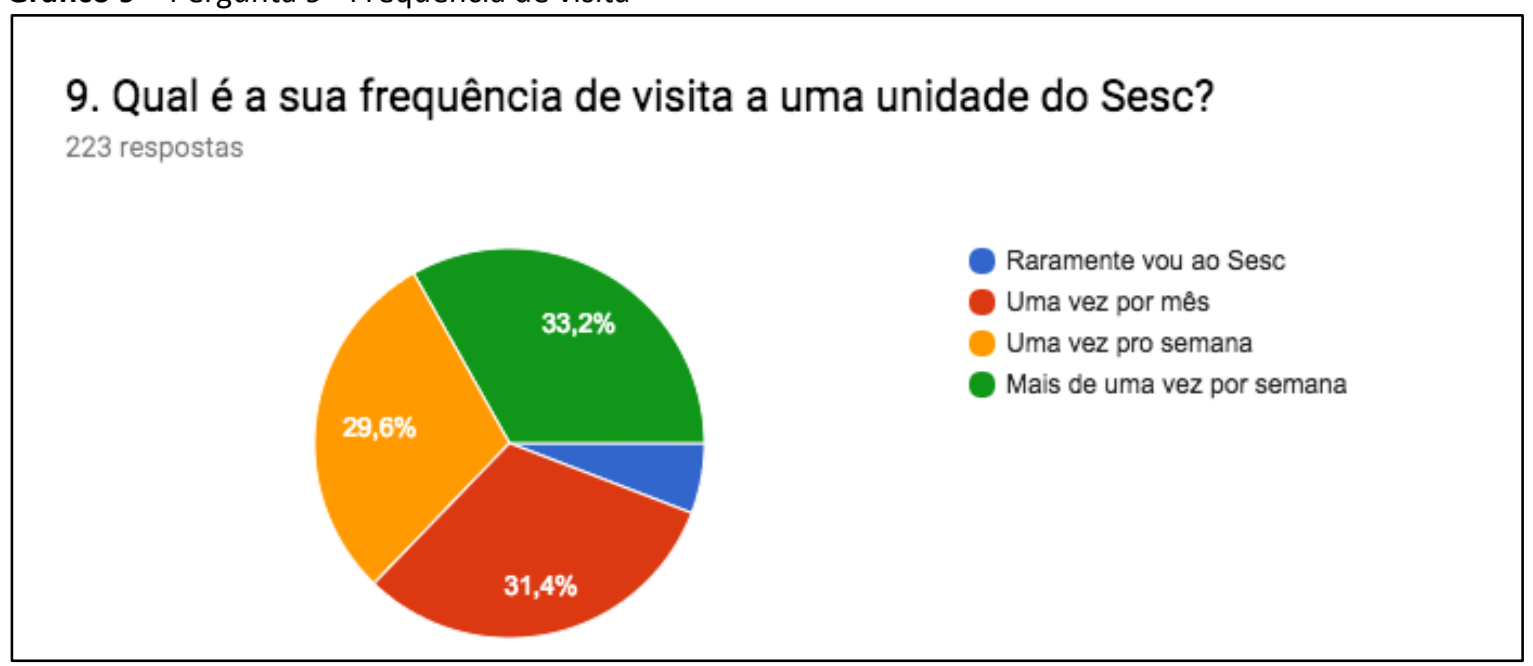

Fonte: Dados da pesquisa

A amostra é assídua, já que a maioria (140) vai pelo menos uma vez por semana a uma unidade do Sesc. Apenas 13 (5,8\%) pessoas responderam que raramente vão ao Sesc.

A pergunta 10 pretendeu saber se há a participação desse público e de seus dependentes em atividades físico-esportivas (hidroginástica, práticas aquáticas, práticas corporais, programa sesc de esportes, ginástica multifuncional e clubes de corrida, caminhada e bicicleta) e de educação não formal do Sesc (Curumim, para as crianças de 7 a 12 anos; e Juventudes, para os adolescentes de 13 a 29 anos). 
Gráfico 10 - Pergunta 10 - Participação em curso permanente

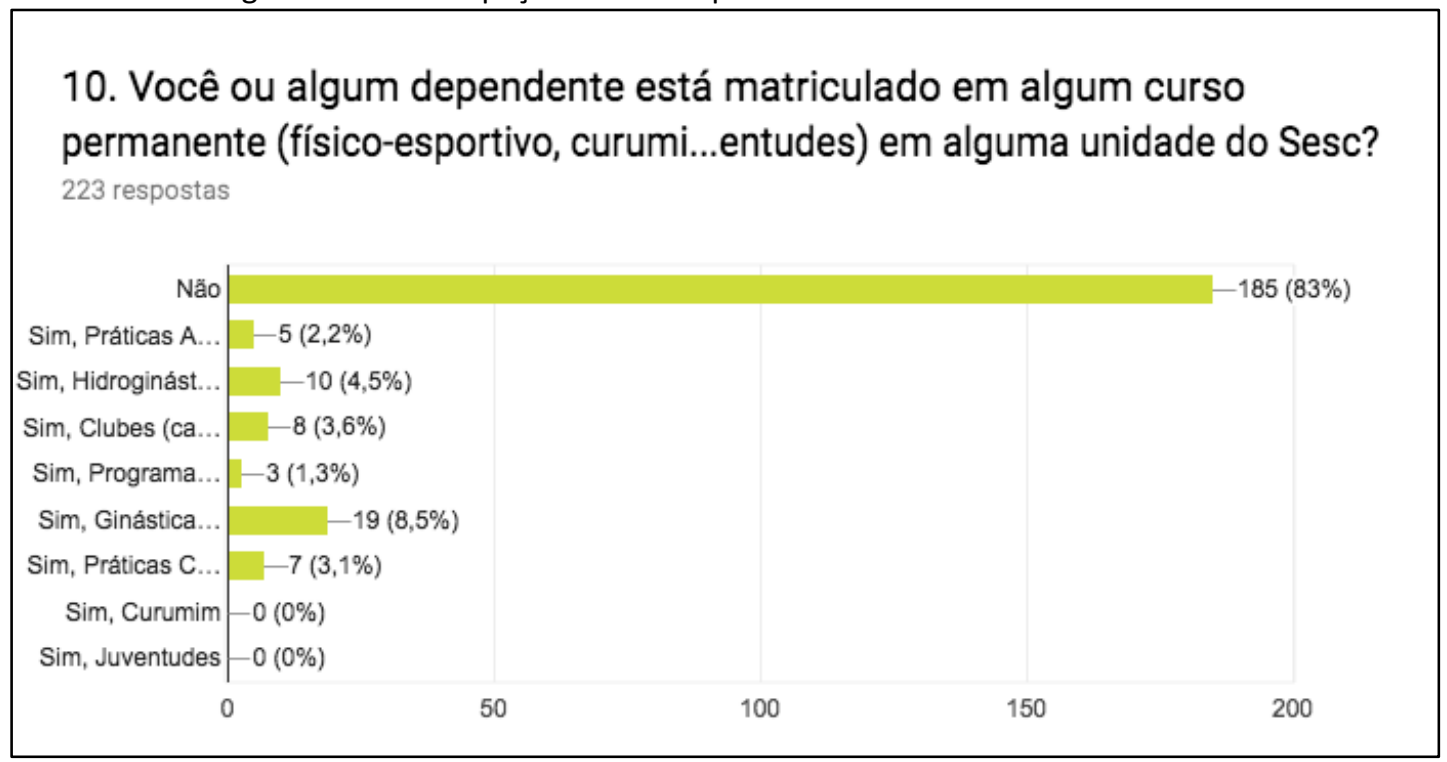

Fonte: Dados da pesquisa

Dentre os respondentes, a maioria não participa dos cursos permanentes, o que pode significar que esses fãs aproveitam meIhor a programação cultural das unidades do Sesc em São Paulo.

As próximas, e últimas, seis perguntas falam sobre a unidade que mais frequenta, mais gosta e menos gosta e porquê. Para as razões, que poderiam ser escolhidas mais de uma, foram utilizadas cinco categorias: ambi- ente (limpeza, arquitetura, equipamentos, espaços), atendimento (funcionários e terceirizados), programação (atividades oferecidas), sociabilidade com outros frequentadores e acessibilidade (localização na cidade, acessibilidade universal, atendimento de transporte público, proximidade de casa ou trabalho). As respostas estão resumidas nas tabelas 1 a 3 , a seguir.

Tabela 1 - Pergunta 11 - Unidades mais frequentadas e razões

\begin{tabular}{cc}
\hline Unidades mais frequentadas & Razões \\
Pompeia (52) & Programação (64\%) \\
Pinheiros (41) & Acessibilidade $(54,7 \%)$ \\
Vila Mariana (19) & Ambiente (34\%) \\
Outras (67) & Atendimento (15,7\%) \\
\end{tabular}

Fonte: Dados da pesquisa 
Tabela 2 - Pergunta 12 - Unidades preferidas e razões

\begin{tabular}{cc}
\hline Unidades preferidas & Razões \\
\hline Belenzinho (66) & Programação (61\%) \\
Pompeiros (51) & Ambiente (56,5\%) \\
Bertioga (14) & Acessibilidade (34,5\%) \\
Outras (42) & Atendimento (27,8\%) \\
\hline Tabela 3 - Pergunte 13 - Unidades que menos gostam e razões & Sociabilidade (16,1\%) \\
\hline Unidades que menos gostam & Razões \\
\hline Carmo (35) & Acessibilidade (52\%) \\
Bom Retiro (18) & Ambiente (26\%) \\
Consolação (13) & Programação (23,3\%) \\
Itaquera (11) & Atendimento (13\%) \\
\hline
\end{tabular}

Fonte: Dados da pesquisa

Sobre o comportamento dessa amostra na vivência nas unidades do Sesc pode-se inferir que os motivos mais fortes, tanto para visitar ou para desgostar de uma unidade, são a programação, o ambiente e a acessibilidade, enquanto que acessibilidade e atendimento não têm tanta influência nas suas escolhas.

\section{CONSIDERAÇÕES FINAIS}

Pode-se afirmar que foi possível apresentar um breve panorama do perfil do aficionado pelo Sesc, presente em grupos da rede social Facebook selecionados pelos pesquisadores, que percebem as relações de hospitalidade e acolhimento dos funcionários, aqui representando o anfitrião.
A hipótese levantada no início deste trabalho, a de que o público fã dos grupos online representaria o público frequentador prioritário da instituição Sesc em São Paulo: o trabalhador do comércio, serviços e turismo, em sua maioria de baixa e média renda, representado pela base da pirâmide (Prahalad, 2017), foi refutada com os resultados da pesquisa socioeconômica. Os respondentes representaram um público de classe social de alto poder aquisitivo, dependente da família e jovem adulto.

A seção de vivência no Sesc também levantou perspectivas para novas pesquisas que poderiam ser realizadas focando na relação instituição-cliente por meio da relação de hospitalidade do funcionário com o público frequentador. 
No caso do Sesc, um centro cultural e de lazer, estabelecimento comercial e que permite a interação social de seus visitantes com a comunidade, o acolhimento se dá desde a chegada deste frequentador até sua despedida. Em seu tempo, hóspede e anfitrião, atores nesse encontro de hospitalidade, recebem seus papéis de forma a construir uma relação de troca. O visitante chega, é recepcionado e acolhido, fica e aproveita seu tempo, sua vivência e experiência na instituição, troca com os funcionários que o atendem e se despede, finalmente.

A dádiva, a troca, o vínculo e a reciprocidade fazem parte da hospitalidade e seus rituais (Boudou, 2012; Grassi, 2011; Montandon, 2011). Cada encontro estudado é único, já que tratamos de pessoas e suas intenções desconhecidas. Ao final, a circulação da dádiva cria um novo ciclo e futuros encontros permitem que a hospitalidade aconteça sempre.

\section{REFERÊNCIAS}

Associação Brasileira de Empresas de Pesquisa. (2016). Critério Brasil 2015 e atualização da distribuição de classes para 2016. Critério de classificação econômica Brasil. Disponível em: <http://www.abep.org/criterio-brasil>

Benveniste, É. (1995). O vocabulário das instituições indo-europeias. Campinas-SP: Editora da UNICAMP.

Binet-Montandon, C. (2011). Acolhida - uma construção do vínculo social. In A. Montandon (Org.), O livro da hospitalidade. São Paulo: Editora Senac.

Boudou, B. (2012). Éléments Pour Une Anthropologie Politique De L'Hospitalité. Revue du MAUSS, 40(2), 267. https://doi.org/10.3917/rdm.040.0267
Boudou, B. (2017). Elementos para uma antropologia política da hospitalidade. In L. B. Brusadin (Org.), Hospitalidade e Dádiva: a alma dos lugares e a cultura do acolhimento. CuritibaPR: Editora Prismas.

Camargo, L. O. de L. (2004). Hospitalidade. São Paulo: Editora Aleph.

Chadborn, D., Edwards, P., \& Reysen, S. (2017). Displaying Fan Identity to Make Friends. Intensities: The Journal of Cult Media, (9), 87-97. Disponível em: $<$ https://www.researchgate.net/profile/Stephen _Reysen/publication/316856709_Displaying_fan _identity_to_make_friends/links/59145fa14585 152e199dc6d2/Displaying-fan-identity-to-makefriends.pdf>.

Gomes, V. ([s.d.]). SESC. Disponível em: <https://www.facebook.com/groups/49843241 0183565/?ref=br_rs. Acesso em: $21 \mathrm{dez} .2017$.

Gotman, A. (2009). O comércio da hospitalidade é possivel? Revista Hospitalidade, 6(2), 03-27.

Grassi, M.-C. (2011). Transpor a soleira. In A. Montandon (Org.), O livro da hospitalidade. São Paulo: Editora Senac.

Karnani, A. (2016). Confusão na Base da Pirâmide no Brasil, 86-94.

Lashley, C. (2004). Para um entendimento teórico. In Em busca da hospitalidade: perspectivas para um mundo globalizado $\left(1^{\circ} \mathrm{ed}\right.$, p. 1-24). Barueri-SP: Manole.

Lugosi, P. (2008). Hospitality spaces, hospitable moments: consumer encounters and affective experiences in commercial settings. Journal of Foodservice, 19(2), https://doi.org/10.1111/j.1745-

4506.2008.00092.x

Martin, K. D., \& Paul Hill, R. (2012). Life Satisfaction, Self-Determination, and Consumption Adequacy at the Bottom of the Pyramid. Journal of Consumer Research, 38(6), 1155-1168. https://doi.org/10.1086/661528 
Mauss, M. (2003). Ensaio sobre a Dádiva. In M. Mauss (Org.), Sociologia e Antropologia. São Paulo: Cosac Naif.

Montandon, A. (2011). Espelhos da Hospitalidade. In A. Montandon (Org.), O livro da hospitalidade (p. 31-37). São Paulo: Senac.

Pitt-Rivers, J. (2012). The Law of Hospitality. HAU: Journal od Ethnographic Theory, 2(1), 501-517.

Prahalad, C. K. (2017). A riqueza na base da pirâmide: erradicando a pobreza com o lucro. Porto Alegre: Bookman.

Reysen, S., Plante, C., \& Chadborn, D. (2017). Better Together: Social Connections Mediate the Relationship Between Fandom and Well-Being. AASCIT Journal of Health, 4(6), 68-73. Disponivel em:

<https://www.researchgate.net/profile/Stephen _Reysen/publication/321671742_Better_Togeth er_Social_Connections_Mediate_the_Relationsh ip_Between_Fandom_and_Well-

Being/links/5a2a78e9aca2728e05db4310/Better -Together-Social-Connections-Mediate-theRelationship->.

Ribeiro, M. N., \& Silva, V. F. da. ([s.d.]). Aficionados pelo SESC-SP. Disponível em: <https://www.facebook.com/groups/24484559 2269792/?ref=br_rs>. Acesso em: 21 dez. 2017.

Sesc São Paulo. (2017). Quem Somos. Disponível em: <https://www.sescsp.org.br/pt/sobre-osesc/quem-somos/>. Acesso em: 28 maio 2017.

Silva, M. F. da. (2013). Centros culturais: análise da produção bibliográfica. Disponível em: $<$ http://periodicos.anhembi.br/arquivos/trabalh os001/420255.pdf>.

Telfer, E. (2004). A filosofia da hospitabilidade. In A. Morrison \& C. Lashley (Orgs.), Em busca da hospitalidade: perspectivas para um mundo globalizado ( $\left.1^{\circ} \mathrm{ed}\right)$. Barueri-SP: Manole.

Tricolor, T., Ferreira, T., \& Oliba, R. ([s.d.]). SESC Troca de Ingressos. Disponível em: <https://www.facebook.com/groups/53738346 9687983/?ref=br_rs>. Acesso em 21 dez. 2017.

\section{APÊNDICE}

Link para o questionário

Nota:

Esta pesquisa foi realizada com fomento do Programa de Suporte à Pós-Graduação de Instituições de Ensino Particulares - PROSUP (CAPES) e da Universidade Anhembi Morumbi.

$\overline{\text { Informações dos autores }}$

\section{Luiz Octávio de Lima Camargo}

Doutor em Ciências da Educação pela Universidade René Descartes-Paris 5, revalidado pela USP-FE como Doutor em História e Filosofia da Educação, Livre Docente em Lazer e Educação pela USP-EACH, Professor titular do Programa de Pós-Graduação em Hospitalidade da Universidade Anhembi Morumbi e professorcolaborador do Programa de Mestrado em Turismo da USP-EACH. E-mail: octacam@uol.com.br.

ORCID: https://orcid.org/0000-0003-4653-1395

\section{Airton José Cavenaghi}

Doutor em História Social. Professor Pesquisador do Programa de Pós-Graduação do Mestrado e Doutorado em Hospitalidade da Universidade Anhembi Morumbi - UAM-SP. Desenvolve pesquisas na área de Ciências Sociais Aplicadas, com enfoque na interpretação das dimensões, resultantes da percepção da hospitalidade na contemporaneidade. E-mail: acavenaghi@gmail.com

ORCID: https://orcid.org/0000-0002-1084-8158

\section{Danilo Cava Pereira}

Mestrando em Hospitalidade pelo Programa de PósGraduação em Hospitalidade da Universidade Anhembi Morumbi - UAM-SP. Desenvolve pesquisas nas áreas de Hospitalidade e Acolhimento, focado no atendimento de Centros Culturais como fator de competitividade na prestação e oferta de seus serviços. Email: danilocava@hotmail.com

ORCID: https://orcid.org/0000-0002-5754-8486

\section{Elizabeth Kyoko Wada}

Bolsista CNPQ Nível 2 com a pesquisa Mobilidade Corporativa na América Latina, concluiu pós-doutorado na UFPR - PPG em Turismo (2016), é Doutora em Ciências da Comunicação pela Universidade de São Paulo (1994), Mestre em Ciências da Comunicação pela Universidade de São Paulo (1989), Especialista em Administração Mercadológica pela EAESP/FGV 
(1982), graduada em Turismo pelo Centro Universitário Ibero Americano Unibero (1979) e em Comunicação Social - Relações Públicas pela Universidade de São Paulo (1980). É Coordenadora do PPG em Hospitalidade da Universidade Anhembi Morumbi (Laureate International Universities) e pesquisadora do Instituto de Pesquisa e Desenvolvimento Social e Tecnológico (ISAM). Atua como docente nas seguintes disciplinas: Gestão e Planejamento Estratégico em Hospitalidade; Hospitalidade, Hostilidade e Stakeholders; Hospitalidade e Competitividade em Serviços; Plano Estratégico de Marketing em Turismo; Tendências, Atualidades e Técnicas em Eventos. Tem experiência nas áreas de Turismo e de Hotelaria na América Latina, com ênfase em Gestão de Meios de Hospedagem e nos seguintes temas: hotelaria, planejamento estratégico, turismo, turismo de negócios (viagens corporativas, eventos empresariais e viagens de incentivo), mobilidade corporativa, serviços e inovação. É docente desde 1981. É diretora administrativo-financeira da ANPTUR (Associação Nacional de Pesquisa e Pós-Graduação em Turismo) e Vice Presidente de Finanças de MPI Brazil Chapter (Meeting Professionals International). É Vice-Presidente do Conselho de Administração de Bourbon Hotéis \& Resorts. E-mail: elwada@anhembi.br

Orcid: http://orcid.org/0000-0001-7016-7365 